\title{
Lawsonia inermis (Lythraceae): From the Wild to the Garden
}

\author{
K. Yakandawala ${ }^{\#}$ and A. M. L. G. Adikari \\ Dept. of Horticulture and Landscape Gardening, \\ Faculty of Agriculture and Plantation Management, \\ Wayamba University of Sri Lanka, \\ Makandura, Gonawila (NWP), Sri Lanka \\ ${ }^{\#}$ Corresponding Author: \\ E-mail: yakandawalakapila@gmail.com
}

\begin{abstract}
This study is a successful effort undertaken to introduce Lawsonia inermis a native plant, to the landscape industry. It can be propagated by seeds. However, seeds are not available throughout the year. Therefore, the present study was conducted with the objective of identifying a suitable propagule and a media to propagate $L$. inermis. Flowering phenology, including animal visitors were observed to elucidate the landscape potential of the plant. In the propagation experiment three maturity stages of stem cuttings viz. softwood, semi hardwood and hardwood were planted in two different media (sand, sand + coir dust 1:1). The layout of the experiment was Randomized completely block design. Twelve weeks after planting, rooting percentage, root dry weight and root number were recorded. Mass flowering was recorded twice a year in L. inermis where $75 \%$ of the canopy was covered with flowers. Flowers are attractive, scented and bloomed in the morning and last for two days. It attracts butterflies, bees and birds. Tree architecture is attractive and the plant can fit into a small space. It is also capable of tolerating adverse environmental conditions. A significant difference was observed in root dry weight and number of roots produced in different treatment combinations and softwood cuttings recorded the highest rooting percentage $(71 \%)$ in sand medium. Therefore, L. inermis can be promoted in urban landscaping and as a solution to the scarcity of planting material, softwood cutting grown in sand media can be recommended as the potential propagule and the media to introduce Lawsonia inermis to the landscape industry in Sri Lanka.
\end{abstract}

KEYWORDS: Landscape, Lawsonia inermis, Native, Phenology, Propagation

\section{Introduction}

Ornamental plants play an important role in many cultures and societies (Heywood, 1999). Hence, ornamental horticultural trade is expanding rapidly and has been recognized as a profitable business all over the world. There is an increasing 
demand for new and exciting species, varieties or cultivars (Mack and Lonsdale, 2001) as the market is saturated with traditionally used species (Heywood, 2003). These new plants may be introduced via wild collections or from plant improvement programmes. Irrespective of the source, most countries import these materials from other countries. Once escaped from gardens or plant propagation units, some of these introduced ornamental plants have the potential to establish themselves and spread in natural ecosystems, causing irreversible damage to the biodiversity, agriculture and recreation. Many such events have occurred globally and such plants are listed under the category of invasive plants.

According to Dehnen-Schmutz et al. (2007), ornamental horticulture has been recognized as the main pathway for plant invasions worldwide. Increasing international trade has been considered a major concern as it enables species to disperse across biographic barriers (Hulme, 2009). There is no exception to Sri Lanka and particularly, ornamental exotic plants dominate the industry. According to a study conducted in Britain (Dehnen-Schmutz et al., 2007), out of a random sample of 534 non-native ornamental species on sale in the nineteenth century, 27\% were recorded growing outside cultivation out of which $30 \%$ were established.

Since ornamental plants play a much smaller role in human affairs than food or fodder plants, little concerted efforts have been made to collect and conserve their genetic resources (Heywood, 1999). Currently used ornamental plants and the diversity of cultivars derived through selection and breeding of plants originally came from wild plants. Still more and more countries are looking at their native flora as a source of new introductions from the wild. The transformation of these introductions of wild growing species into potential commercial cultivars was largely undertaken by highly skilled, observant, and entrepreneurial nurserymen, many of whom were very talented plantsmen who initiated plant improvement programmes themselves by selection and breeding (Heywood, 2003).

Sri Lanka, together with Western Ghats, has been identified as one of the 25 biological hot spots of the world and is further listed among the eight 'hottest hotspots' (Myers et al., 2000). This diverse floristic wealth of Sri Lanka harbors over 3492 floral species including Gymnosperms and Pteridophytes of which 943 are endemic (Red list 2012). This floristic wealth can be tapped to introduce wild plants into the landscape industry. These native plants can be expected to tolerate biological and environmental stresses that often characterize the landscape sites in which they were expected to perform (Schutzki and Pellett, 2002 and Abbey, 2004). Further, native plants will be less demanding. Hence the maintenance cost of landscapes will be reduced and as a result, designers will be able to design landscapes in a sustainable manner.

Native species are usually valued above introduced species by ecologists and environmentalists. However, introduced ornamentals are often given an equal or higher preference by horticulturists (Myers and Bazley, 2003). Common arguments 
forwarded concerning the importance of native plants include that; they are less costly to maintain as they have evolved and adapted under local environmental stresses thus able to tolerate droughts; once established they require no irrigation, weed control and fertilization; and they are resistant to most pests and diseases. Thus, native plants are believed to be superior to exotic plants because of their better growth, reduced likelihood to become invasive, direct and indirect biodiversity value and contribution to local sense of place.

Another dimension of native plants is their historical and cultural interest. Some plants play a significant role in native culture. Many species have been reported with food or medicinal value. Others have been used for cordage, textiles, dyes or similar domestic purposes (Taylor, 1988; Gilbert and Anderson, 1998; Worell, 1998; Kendle and Rose, 2000; Abbey, 2004). Further, planting an urban environment with native plants plays an important role in the conservation of insects, birds and other forms of wild life (Burghardt, 2009).

In this context, Lawsonia inermis L. (Lythraceae) commonly known as 'Henna'was identified as a wild plant which has a potential to be promoted as an ornamental plant in the landscape industry. In addition to its potential landscape value, it has been used for medicinal and cosmetic purposes since ancient times in cultures of North Africa and Asia (Semwal et al., 2014). Literature indicates that $L$. inermis played an important holistic role in the daily lives of some ancient cultures, providing psychological benefits and traditionally being used in various festivals and celebrations as well as being used for personal adornment (Hema et al., 2010). All parts of the plant have a medicinal value (Chaudhary et al., 2010) and are used in traditional medicine to treat a variety of ailments including rheumatoid arthritis, headache, ulcers, diarrhea, leprosy, fever, leucorrhoea, diabetes and cardiac diseases in different parts of the world including Sri Lanka (Chaudhary et al., 2010; Jayaweera, 1981; Reddy, 1988; Semwal et al., 2014).

In Sri Lanka either, internationally planted or naturally occurring $L$. inermis plants can be seen in some home gardens. However, due to the scarcity of propagules it is not a popular plant in commercial nurseries and people use root balled plants from the wild in landscaping. This can cause a negative effect on the environment. Therefore, this study was conducted with the objective of identifying a suitable vegetative propagation technique to propagate $L$. inermis and to investigate the flowering phenology and animal visitation in view of promoting this plant in the landscape industry.

\section{Materials and Methods}

\section{Field Survey}

A field surveys was conducted in the Kurunegala district (Intermediate zone) and two natural populations were selected in Ibbagamuwa area and Makandura area. 
Planting material was collected from Makadura for the propagation experiment and phenological observations were made in Ibbagamuwa population.

\section{Flowering Phenology}

Ten adult individual plants were selected and flowering phenology was recorded by visual observations at one week interval for a year. When flower buds were present, five buds from each plant was tagged and observations were made daily throughout the flowering season to determine the time, duration and frequency of flowering. The colour of the flowers and fruits were recorded using RHS colour chart (Royal Horticultural Society, 2001). Animal visitation to the flowers was recorded throughout the flowering season.

\section{Propagation Experiment}

The experiment on vegetative propagation of stem cuttings was conducted at the Faculty of Agriculture and Plantation Management, Wayamba University of Sri Lanka, Makandura, situated in the Low country intermediate zone (IL1). Stem cuttings were obtained from the non-flowering, healthy, vigorously growing mother plants located in the Makandura area.

Cuttings of $20 \mathrm{~cm}$ length were made from these plants to include at least three nodes on each cutting to represent softwood, semi hardwood and hardwood cuttings. The cuttings were planted in black polythene bags $(6 \mathrm{~cm} \times 8 \mathrm{~cm}$, gauge 150) with drainage holes at the base. These were placed in a propagator, inside a net house, in two different potting media namely sand and sand: coir dust $(1: 1)$. The propagators were covered with transparent polythene (gauge 500) and the net house was covered with $75 \%$ shade nets. During planting, the bases of the cuttings were dipped into a rooting hormone consisting of $0.3 \%$ IBA. The top ends of the semi hardwood and hardwood cuttings were covered with a Bordeaux mixture. The cuttings were irrigated twice a week to field capacity and foliar fertilizer (Maxicrop $2.5 \mathrm{ml} / \mathrm{L}$ ) was applied once in three-weeks. In addition, fungicide (Folicur $0.35 \mathrm{ml} / \mathrm{L}$ ) was sprayed once in three weeks as a preventive treatment against fungal infections.

\section{Experimental Design}

The experiment included six treatment combinations viz. three maturity stages of cuttings vs. two types of media (Table 1) arranged in a randomized complete block design with three blocks. Three propagators were used in the experiment and each propagator was considered as a block. Twenty-one cuttings were used in a single plot to represent a treatment combination and six such plots were used in a single block. Altogether 126 cuttings were used in a single block to represent six treatment combinations. Therefore, in the experiment 378 cuttings were used to represent three blocks. 
Table 1: Details of the treatment combinations used in the experiment

\begin{tabular}{ccc}
\hline $\begin{array}{c}\text { Treatment } \\
\text { Combination }\end{array}$ & $\begin{array}{c}\text { Maturity Stage of } \\
\text { Cuttings }\end{array}$ & Potting Mixture \\
\hline T1 & Softwood & Sand \\
T2 & Softwood & Sand + Coir dust $(1: 1)$ \\
T3 & Semi hardwood & Sand \\
T4 & Semi hardwood & Sand + Coir dust $(1: 1)$ \\
T5 & Hardwood & Sand \\
T6 & Hardwood & Sand + Coir dust $(1: 1)$ \\
\hline
\end{tabular}

\section{Data Recording and Data Analysis}

The rooting percentages, number of roots per cutting and root dry weight (oven dried at $80^{\circ} \mathrm{C}$ for 48 hours) were recorded from all the plants, 12 weeks after planting as destructive samples. Data was analyzed by fitting a linear logistic model and the means of root dry weight were compared by the Least Significant Difference Test. Count data was analyzed using the CATMOD procedure. The data was analyzed using Statistical Analysis System (SAS) package, 1998.

\section{Results}

\section{Flowering Phenology}

In L. inermis, the flowers are borne in an inflorescence which is an axillary or terminal panicle. Flower buds are round in shape and an individual bud took 20 days $( \pm 1)$ to reach the unfolding stage. Flowers started to bloom in the afternoon and reached the full bloom stage 9 hours later in the following day morning. A fragrance was present in slightly opened buds and it reached the maximum level at full bloom stage (Table 2). Flower colour belongs to the yellow group 4B while mature fruits are yellow green 144A and dried fruits are greyed orange 165A (RHS Colour Chart, 2001).

Table 2: Lawsonia inermis - from flower bud to senescence

\begin{tabular}{cccccc}
\hline Event & $\begin{array}{c}\text { Duration } \\
\text { of a Bud }\end{array}$ & $\begin{array}{c}\text { Initiation of } \\
\text { Unfolding }\end{array}$ & $\begin{array}{c}\text { Half Bloom } \\
\text { Stage }\end{array}$ & $\begin{array}{c}\text { Full Bloom } \\
\text { Stage }\end{array}$ & $\begin{array}{c}\text { Initiation } \\
\text { of } \\
\text { Senescence }\end{array}$ \\
\hline Duration & 20 days & $4.30-7.30 \mathrm{pm}$ & $\begin{array}{c}12.30-2.00 \\
\text { am }\end{array}$ & $\begin{array}{c}6.30-9.30 \\
\text { am }\end{array}$ & $\begin{array}{c}\text { After } 2 \\
\text { days }\end{array}$ \\
\hline Fragrance & Absent & $\begin{array}{c}\text { Slightly } \\
\text { present }\end{array}$ & present & Very strong & Absent \\
\hline
\end{tabular}


An average of 242 buds $( \pm 40.5)$ was recorded in a given panicle. However, these buds did not bloom simultaneously. Once the blooming initiated, a panicle reached to full bloom stage (85\% flowering) in 5 days after which flowering intensity reduced to $10 \%$ and terminated after 7 days. Flowers were visited by stingless honey bees (Trigona iridipennis), common bees (Apis cerana) and butterflies. Butterfly species were identified as Mycalesis perseus typhlus 'Common Bushbrown' (Nymphalidae) and Ypthima ceylonica 'White Four-ring' (Nymphalidae). Mass flowering was observed in L. inermis twice a year from February to March and during June - July. During mass flowering $75 \%$ of the canopy was covered with flowers.

\section{Growth Performance of Cuttings}

\section{Rooting of Cuttings}

Rooting was recorded in all the three maturity stages of cuttings. However, highest average rooting percentage was recorded in softwood cuttings grown in sand media (71\%) followed by softwood cutting grown in sand + coir dust media (44\%) (Figure 1).

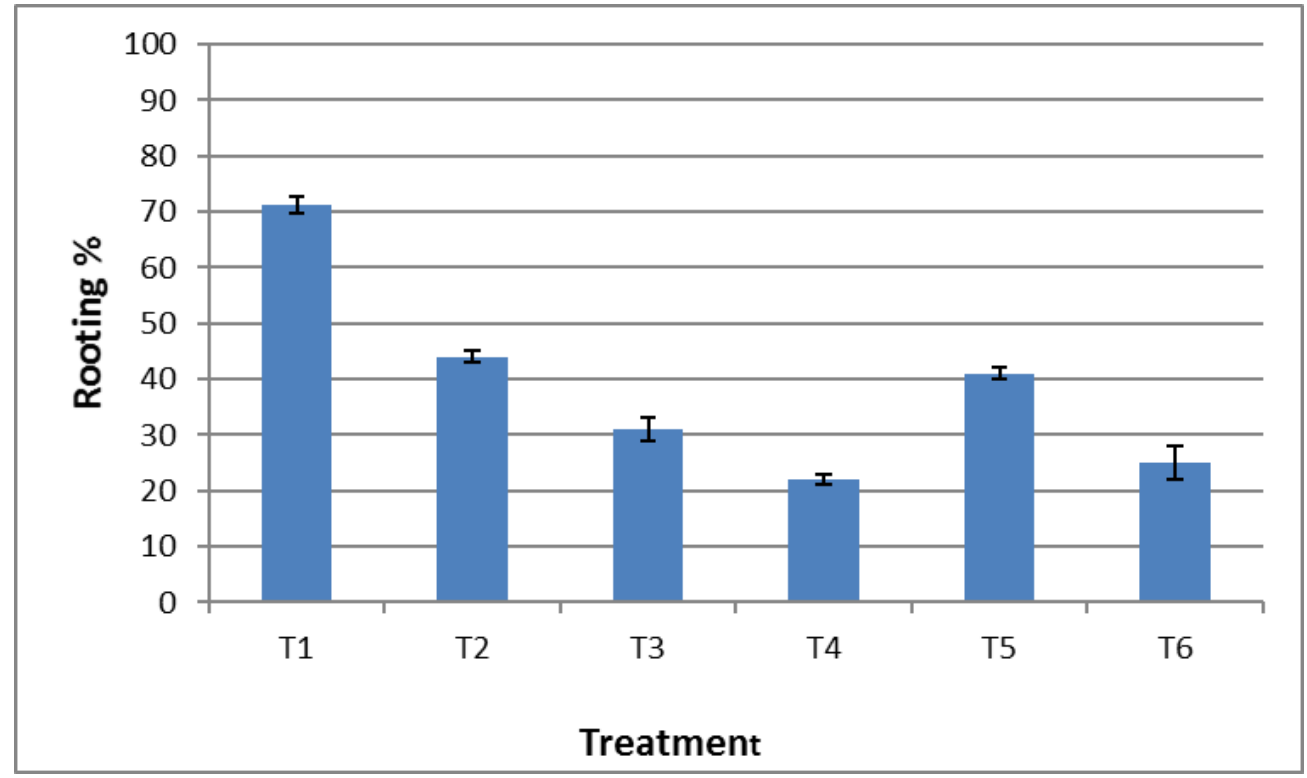

Figure 1: Rooting percentage of cuttings in different treatments

\section{Root Dry Weight}

There was a significant effect of maturity stage of cuttings and potting media on root dry weight (Table 3). However, there was no interaction between maturity stage of cuttings and potting media on root dry weight. 
Table 3: Effect of maturity stages of cuttings and potting media on root dry weight

\begin{tabular}{ccc}
\hline Source & Mean Root Dry Weight $(\mathbf{g})$ & Probability \\
\hline Maturity stage of cuttings & 0.0252 & 0.0007 \\
Potting media & 0.0172 & 0.0006 \\
R - square & & 0.1622 \\
CV & & 101.51 \\
\hline
\end{tabular}

Probability value $<0.05$ - significantly different

Compared with semi hardwood, softwood and hardwood cuttings recorded a significantly higher root dry weight (Table 4) and it was significantly high in sand medium compared to sand + coir dust (1:1) medium (Table 5).

Table 4: Mean root dry weight in different maturity stages of cutting

\begin{tabular}{cc} 
Maturity Stage & Root Dry Weight $(\mathbf{g})$ \\
\hline Softwood & $0.01150^{\mathrm{a}}$ \\
Semi hardwood & $0.0038^{\mathrm{b}}$ \\
Hardwood & $0.0097^{\mathrm{a}}$ \\
\hline
\end{tabular}

Means in a column followed by the same letters are not significantly different at 0.05 level

Table 5: Mean root dry weight in different potting media

\begin{tabular}{cc}
\hline Potting Media & Root Dry Weight $(\mathbf{g})$ \\
\hline Sand & $0.0114^{\mathrm{a}}$ \\
Sand + Coir dust $(1: 1)$ & $0.0058^{\mathrm{b}}$ \\
\hline
\end{tabular}

Means in a column followed by the same letters are not significantly different at 0.05 level

\section{Root Number}

There was a significant effect of maturity stage of cuttings and potting media on root number (Table 6). However, the interaction was not statistically significant between maturity stage of cuttings and potting media. According to contrast analysis, the number of roots was significantly high in softwood cuttings (8.93) compared to semi hard wood (7.97) and hardwood cuttings (7.28), while a significant difference was not observed between semi hardwood and hardwood cuttings (Table 7). Therefore, softwood can be considered as the best cutting type and sand medium could be considered as the best medium. 
Table 6: Effect of maturity stages of cuttings and potting media on number of roots

\begin{tabular}{ccc}
\hline Source & Chi - Square & p - Value \\
\hline Cutting type & 191.18 & $<0.0001$ \\
Media & 67.92 & $<0.0001$ \\
Likelihood ratio & & 0.0004 \\
\hline
\end{tabular}

Probability value $<0.05$ - significantly different

Table 7: Contrast analysis of maturity stage of cutting and number of roots

\begin{tabular}{ccc}
\hline Cutting Type & Chi - Square & p - Value \\
\hline Softwood vs. Semi hard wood & 138.87 & $<0.0001$ \\
Softwood vs. Hardwood & 111.12 & $<0.0001$ \\
Semi hardwood vs. Hard wood & 2.12 & 0.1453 \\
\hline
\end{tabular}

Probability value $<0.05$-significantly different

\section{Discussion}

Cities encompass $53 \%$ of the world's human population (Demographia World Urban Areas, 2014) but take up less than 3\% of the land surface (Beillo, 2012). This shows that urban areas may not be priority areas for conservation of threatened or rare native plants; however, they may be the most suitable place for many people to integrate with nature. In this context it is appropriate to introduce more native plants to urban areas. Professionals engaged in urban development programmes are now beginning to use more native plant species in urban environments than they have in the past with hopes of boosting the local biodiversity. A problem they encounter immediately is that most native plant species are not freely available in the nurseries. Hence it is important to develop simple protocols to propagate native plants. Similar situation is observed with L. imermis, where planting material is not available in the nurseries.

Although seeds can be used to propagate $L$. inermis, sexual propagation is unreliable because of the short viability, unavailability throughout the year and pest and disease problems (Singh et al., 2012). According to Jansen and Cardon (2005) the seed coat of $L$. inermis is hard and seeds have to be pre-germinated before sowing. Though micropropagation techniques were developed (Rout et al., 2001), it is associated with a high cost. These factors hinder the availability of planting material in nurseries. Therefore, it is necessary to introduce a low cost vegetative propagation technique to produce planting material at large scale. 
According to the present study, all the cutting types are capable of producing roots in a growing medium. However, softwood cuttings grown in sand medium recorded the highest survival $(71 \%)$ and growth performance (viz. root dry weight and root number). Hence, softwood cuttings grown in sand medium can be recommended as a potential propagule and medium to introduce this plant to the landscape industry. Similar studies conducted on other native plants such as Osbeckia octandra (Yakandawala et al., 2013) and Murraya paniculata (Yakandawala and Welideniya, 2008) also recommended soft wood cuttings as the best cutting type and sand media as the best media.

Lawsonia inermis is a naturally occurring plant in Sri Lanka, distributed in the wet, intermediate and dry zone of the country (Verdcourt, 1995). Hence it has evolved and adapted to local conditions over thousands of years. Therefore, it can be introduced as a low maintenance landscape plant. Lawsonia inermis can be considered as a shrub or a small tree which attains a height of $1.5-7 \mathrm{~m}$ (Verdcourt 1995), having a narrow canopy. Hence it can easily fit into a smaller space as space is a limited factor in urban areas. Environmental conditions tend to be more varied in urban areas. Particularly light, wind, temperature and soil conditions can change abruptly from one spot to another $(\mathrm{Ng}, 2010)$.

Hence, plant adaptability to unfavorable and unpredictable conditions is important in urban areas. Lawsonia inermis can survive near watercourses to semi-arid regions and isadapted toa wide range of conditions. It can withstand low air humidity and drought (Orwa et al., 2009). Therefore, it is an ideal candidate for urban greening. Tree architecture of L. inermis is attractive and it bears small leaves and the canopy is open. Hence it can be used at the back of a mixed border.

The plant tolerates pruning and can be promoted to establish live fences.Mass flowering was observed twice a year and the canopy at its full blooming stage enhances the aesthetic value. As flowers produce fragrance in the morning (Table 2 ), it enhances the air quality in urban settings. Flowers attract butterflies and other insects. According to Orwa et al. (2009), birds feed on the fruits. Hence, it can also be promoted in wildlife gardening which is a fairly new concept in Sri Lanka.

By considering above facts, in addition to the potential landscape value, this plant can be promoted as a multipurpose plant. As most of the human dominated landscape spaces in Sri Lanka are filled with exotic ornamentals. Thereby the concept of sustainable landscape design approaches can be supported. Past landscaping paradigms have treated plants as elements for decorations and other functional aspects and ignored its environment benefits. However, many ecological roles that plants play in human dominated ecosystems are now valued. In the light of hitherto discussed facts we can promote L. inermis in sustainable urban greening activities. 


\section{Conclusions}

The present study highlights the importance of introducing native plants in urban landscaping in Sri Lanka and recognizes the potential capability of Lawsonia inermis as an ideal candidate. The plant is capable of tolerating urban stresses and softwood cuttings grown in sand media can be recommended as the best cutting type and potting media to introduce this plant to the nursery sector. Apart from aesthetic benefits, it can be used to get other functional and environmental benefits and it can be promoted as a multipurpose ornamental plant.

\section{References}

Abbey, T. M. (2004). "Alternatives for invasive ornamental plant species". The Connecticut Agricultural Experiment Station for the Connecticut Invasive Plant Working Group, New Haven CT.

Beillo, D. (2012). “Gigalopolises: Urban land area may triple by 2030”. Scientific American, $18^{\text {th }}$ September, 2012.

Burghardt, K. T., D. W. Tallamy and W. Gregory Shriver (2009). "Impact of native plants on bird and butterfly biodiversity in suburban landscapes". Conservation Biology, 23(1): 219-224.

Chaudhary, G., S. Goyal and P. Pooniya (2010). "Lawsonia inermis Linnaeus: A phytopharmacological review". International Journal of Pharmaceutical Sciences and Drug Research, 2(2): 91-98.

Dehnen-Schmutz, K., J. Touza, C. Perrings and M. Williamson (2007). "The horticultural trade and ornamental plant invasions in Britain". Conservation Biology, 21(1): 224231.

Demographia World Urban Areas (2014). Available online: http://www.demographia.com/db-worldua.pdf

Gilbert, O. L. and P. Anderson (1998). “Habitat Creation and Repair”. Oxford University Press, Oxford, UK.

Hema, R., S. Kumaravel and S. Gomathi (2010). "Gas Chromatography - Mass Spectroscopic analysis of Lawsonia inermis Leaves". New York Science Journal, 3(12): 99-101.

Heywood, V. H. (1999). "Use and potential of wild plants in farm households". FAO Farm systems management series, Issue 15, Food and Agriculture Organization.

Heywood, V. (2003). "Conservation and sustainable use of wild species as source of new ornamentals". Proceedings of the sustainable use of plant biodiversity. Acta Horticulturae, 589: 43-53. 
Hulme, P. E. (2009). "Trade, transport and trouble: managing invasive species pathways in an era of globalization". Journal of applied Ecology, 46: 10-18.

Jansen, P. C. M. and D. Cardon (2005). "Prota: Plant resources of tropical Africa 3: Dyes and tannins". Wageningen, Netherlands.

Jayaweera, D. M. A. (1981). "Medicinal Plants used in Ceylon". National Science Council of Sri Lanka, Colombo. 3: 287.

Kendle, A. D. and J. E. Rose (2000). "The aliens have landed!. What are the justifications for 'native only' policies in landscape plantings". Landscape and Urban Planning, 47: 19-31.

Mack, R. N. and W. M. Lonsdale (2001). "Humans as global plant dispersers: getting more than we bargained for". BioScience, 51: 95-102.

Myers, J. H. and D. Bazley (2003). "Ecology and control of introduced plants". Cambridge University Press, UK, 1-13.

Myers, N., R. A. Mittermeier, C. G. Mittermeier, G. A. B. da Fonseca and K. Jennifer (2000). "Biodiversity hotspots for conservation priorities". Nature, 403: 853-858.

Ng, E. (2010). "Designing high-density cities for social and environmental sustainability". Earthscan Publications Ltd., London, UK, 342.

Orwa, C., A. Mutua, R. Kindt, R. Jamnadass and S. Anthony (2009). "Agroforestry Database: a tree reference and selection guide version 4.0". World Agroforestry Centre, Kenya, 1-5.

Reddy, K. R. (1988). "Folk medicine from Chittoor district Andhra Pradesh, India used in the treatment of jaundice". International Journal of Crude Drug Research, 26: 137140.

Rout, G. R., G. Das, S. Samantaray and P. Das (2001). "In Vitro micropropagation of Lawsonia inermis (Lythraceae)". Revista de Biología Tropical, 49: 3-4.

Schutzki, R. E. and H. Pellett (2002). "Developing the landscape potential of native plant species from the great lakes region of the United States". Plant Evaluation. Nursery and Landscape Projects and Programmes. Available online: http:// landscapecentre.org/files/LPDC_annualreport_prf.

Semwal, R. B., D. K. Semwal, S. Combrinck, C. Cartwright-Jones and A. Viljoen (2014). "Lawsonia inermis L. (henna): Ethnobotanical, phytochemical and pharmacological aspects". Journal of Ethnopharmacology, 155(1): 80-103.

Singh, P., K. Jain, B. Jain and S. Khare (2012). "In vitro micropropagation of Lawsonia inermis: an important medicinal plant". International Journal of Current Research and Review, 4(22): 29-34. 
Taylor, H. W. (1988). “A regional view”. American Nurseryman, 167(12): 27-35.

Verdcourt, B. (1995). "Lythraceae, A revised handbook to the flora of Ceylon”.

Worell, R. (1998). “Choosing seed sources for native species”. Tree News. Autumn, 12-14.

Yakandawala, K. and W. T. M. Welideniya (2008). "Landscape potential of the native plant Murrayapaniculata (L.) Jack (Rutaceae)". Abstracts of the $2^{\text {nd }}$ International Symposium, Sabaragamuwa University of Sri Lanka, 39.

Yakandawala, K., M. D. C. P. Weerasinghe and S. A. E. C. Wijesinghe (2013). "Osbeckia octandra: A potential shrub for urban environment". Acta Horticulturae, 999: 301306. 